Victoria K. Alogna

University of Otago

William James Building, 275 Leith Walk

Dunedin 9016, New Zealand

e-mail: victoria.alogna@gmail.com

\title{
Jesse Bering
}

University of Otago

William James Building, 275 Leith Walk

Dunedin 9016, New Zealand

e-mail: jesse.bering@otago.ac.nz

\section{Evan Balkcom}

University of Otago

William James Building, 275 Leith Walk

Dunedin 9016, New Zealand

e-mail: evanbalkcom@gmail.com

\section{Jamin Halberstadt}

University of Otago

William James Building, 275 Leith Walk

Dunedin 9016, New Zealand

e-mail: jhalbers@psy.otago.ac.nz

\begin{abstract}
:
Scientific interest in religion often focusses on the "puzzle of belief": how people develop and maintain religious beliefs despite a lack of evidence and the significant costs that those beliefs incur. A number of researchers have suggested that humans are predisposed towards supernatural thinking, with innate cognitive biases engendering, for example, the misattribution of intentional agency. Indeed, a number of studies have shown that nonbelievers often act "as if" they believe. For example, atheists are reluctant to sell the very
\end{abstract}


souls they deny having, or to angrily provoke the God they explicitly state does not exist. In our own recent work, participants who claimed not to believe in the afterlife nevertheless demonstrated a physiological fear response when informed that there was a ghost in the room. Such findings are often interpreted as evidence for an "implicit" belief in the supernatural that operates alongside (and even in contradiction to) an individual's conscious ("explicit") religious belief. In this article, we investigate these arguably tenuous constructs more deeply and suggest some possible empirical directions for further disentangling implicit and explicit reasoning.

Keywords: unbelief, supernatural belief, implicit belief, explicit belief.

\section{Introduction}

Religion presents a puzzle to cognitive scientists [24], [49], [61]: believers sacrifice substantial material and cognitive resources in adherence to beliefs for which they have no evidence. One proposed answer to the puzzle is that humans are cognitive predisposed, if not evolutionarily hard wired, to hold supernatural beliefs [9], [14]. The strongest evidence for these provocative claims is the fact that, in some situations, even die-hard nonbelievers behave as though they believe [10], [34], [39], [42], [43], [47]. People may, for example, feel uncomfortable taking God's name in vain, even though they feel confident that God does not exist, or refuse to sell their soul for cash despite believing that they do not possess one. Such contradictions are sometimes taken to reveal beliefs that people did not know they had.

We argue, however, that such behaviors raise more - and more interesting - questions than they answer: Are behaviors evidence of belief, a form of belief, or something else altogether? When self-report and behavior conflict which one, if either, reflects a person's "real" belief? If both do, how is the contradiction cognitively and emotionally managed? In the current paper, we first discuss in more detail the puzzle of belief and the "solution" of cognitive predisposition. We then consider the meaning of "belief" in the cognitive sciences, and three attempts to incorporate "behaving as if one believes" into these frameworks. While we do not resolve the questions above, we hope to provide researchers and theorists with enough conceptual clarity to bring them closer to their own answers.

\section{The Puzzle of Religious Belief}

The importance of religious belief is difficult to overstate: a recent study of 230 countries estimated that $84 \%$ of the world's population was affiliated with an established religious group [61]. Furthermore, it is likely that many of the "nonreligious" people surveyed are functionally religious as well; other studies have estimated that only $7 \%$ of the global population claims not to believe in a god or gods [44], [78].

The near universality of religious belief is something of a conundrum, not only because of its basis in empirically unsubstantiated faith, but also because it comes with nontrivial material and social costs. These costs can take the form of sacrifices (e.g., tithing, time-consuming rituals, proscriptions on food or sex, etc.) or, in more extreme cases, physically demanding or even dangerous pilgrimages and practices. For example, every 12 years Hindus from around the world travel to Pryang, India to bathe in the waters of the Ganges and Yamuna rivers as part of the Purna Kumbh Mela pilgrimage [24], [49]. The financial costs associated with such a pilgrimage are significant, and the Purna Kumbh Mela presents additional health risks as well: the Ganges is one of the most polluted, and polluting [46], rivers on the planet and poses a serious health threat [16]. (For a discussion on the possible social signaling function of religious rituals, see [71].) 
Given the ubiquity and costliness of religious devotion, it is easy to see why social scientists have struggled to resolve the "puzzle of belief." One proposed resolution is that humans are cognitively "predisposed" to be religious, that our evolved cognitive architecture innately biases us to think in supernatural terms - to envision the self as surviving biological death, for example [11], to see patterns in ambiguous stimuli [33] and intentional agency where none exists [6], or to think that important events happen "for a reason" [3], [38]. Thus, the logic goes, all humans, even nonbelievers, are believers (e.g., see [9]; [14]).

In a study on afterlife beliefs by Bering [10], for instance, some individuals who selfidentified as "extinctivists" (i.e., they explicitly and confidently believe that personal consciousness ceases at death) nevertheless reasoned that a dead person retained psychological capacities (e.g., that the person would "know" that they were dead). Even participants who consistently rejected the possibility of postmortem emotional and epistemic states struggled when reasoning about them (e.g., it took them longer to say that the deceased no longer believed or loved than to say that he or she could no longer be hungry or sleepy). Bering interpreted this as evidence of a simulation constraint on humans' ability to consciously represent the absence of consciousness in dead others, a cognitive hurdle that lends itself to afterlife ascriptions of certain categories of mental states over others - even among those who profess a strident materialist stance.

Other studies have led to similar findings, all indicating a discrepancy between what people say they believe and how they actually reason. For example, Haidt, Bjorkland, and Murphy [34] notoriously observed people's reluctance to sell their soul to the experimenter, even when they denied believing in souls and were told the sales contract was not legally binding and would be shredded following the experiment (see also $[62]^{1}$ ). In her work on teleofunctional reasoning (i.e., assumptions about the purpose or design of an object, in this case the universe), Kelemen and her colleagues [39], [42], [43] have shown that people who explicitly reject beliefs about intelligent design or a purposeful universe nevertheless endorse such statements under time pressure. Barrett and Keil [5] demonstrated that people frequently describe God in human terms in direct contrast with their explicit God beliefs (e.g., that an "omnipresent" God can in fact only attend to one problem at a time). Lindeman, Heywood, Riekki, and Makkonen [47] reported that atheists were just as physiologically uncomfortable (as measured via skin conductance) as believers when challenging God (at the experimenter's request) to harm their friends and family, even though they claimed to find the challenges less unpleasant than did believers.

Studies of behavior also show that people are similarly influenced by exposure to religious and supernatural stimuli, regardless of their professed beliefs. Just like believers, nonbelievers act more prosocially after being exposed subliminally to religious words (e.g., [63]; [68]) and demonstrate increased self-control (e.g., [45]; however, see [31]). And although Bering, McLeod and Shackelford [13] did not ascertain participants' explicit belief in the afterlife, individuals who were casually informed that a ghost had recently been spotted in their laboratory were significantly less likely than control participants to cheat on a competitive task when left alone in that room.

In a recent follow-up to Bering et al. [13], we examined whether the introduced presence of a "ghost" would influence people's physiological responding, and if so, whether these low-level bodily effects would be discernable even among those who self-identified as extinctivists [70]. Participants engaged in a mindfulness task in a laboratory room. In the experimental condition, participants were informed that a university employee had recently died in the room and as a casual aside, that the ghost of this person had recently been seen in the room. Those in the control condition did not hear anything about a death. In both conditions, participants were distressed (according to measures of skin conductance) when a remote-controlled light flickered off and on for several seconds, but those who had been told the ghost story were significantly more so. Critically, the difference between conditions did not depend on participants' self-reported belief in the afterlife: those who denied the possibility of postmortem existence were just as likely as those who accepted it to respond physiologically "as if" they believed the event was due to the ghost. Irrespective of their explicit afterlife beliefs, those in the ghost condition also reported being significantly more afraid than those in the control condition. 


\section{Disentangling the Many Strands of "Belief"}

It is clear that those who explicitly reject the supernatural sometimes act and reason in a manner inconsistent with their stated beliefs. However, at the moment, precisely what such discrepancies reveal remains unclear. When people refuse to sell the soul they claim not to have, or fear the consequences of challenging a god they do not believe in, or tacitly endow the dead with mental abilities after denying they have any capacities at all, is this somehow revealing of their "real" beliefs? If so, are they unaware of their real beliefs? Are they aware but deceiving themselves, and, if they are, to what end? Do they momentarily believe?

To begin answering such challenging questions, we must first consider what it means to "believe" in the broader context of the cognitive sciences. Generally, cognitive scientists agree that beliefs are stable mental representations of the world, including those related to goals and personal identity (e.g., [18]). Something like this characterization is also apparent in the lay conception of belief. In a sample of around 1000 British people, Pechey and Halligan [57] found that 89\% described it as a "strongly held conviction," $84 \%$ as a "framework for explaining how things are or should be," and $81 \%$ as "right and/or true." Furthermore, most respondents reasoned that beliefs were discrete states, separable from but capable of influencing other mental states (i.e., attitudes, thoughts, feelings) and causing behaviors.

Beyond this general consensus, however, the picture is much murkier. Operational definitions of belief are vague and inconsistent [51], but commonly involve associations between objects and attributes [22]; [41] and/or propositions (e.g., [25]). In the case of the latter, belief might be conceptualized as the acceptance of the existence or actuality of an object, as in the belief that "ghosts exist" [25], whereas in the former, belief captures any association between a concept and any property, as in the belief that "ghosts are scary" [22]; [41]. Perhaps most notable and contentious is investigators' frequent distinction between implicit (or intuitive) and explicit (or reflective) belief. Although these constructs are themselves often conflated and contested, and the relationship between them unclear, the general distinction is useful for unraveling the relationship between religious belief and behavior.

\section{Explicit and Implicit Belief}

Operational definitions of explicit religious belief tend to be vague and multifaceted [56]. Researchers have defined explicit religious belief in terms of religious identity (e.g., selfclassification as "Christian" or "Muslim"), behavior (e.g., church attendance or frequency of prayer), and endorsement of religious or supernatural claims, even though these measures are empirically distinct (albeit usually correlated). For instance, someone with an extrinsic religious orientation (i.e., who uses religion for social and material benefits, such as social advancement) may not endorse supernatural claims (e.g., the idea that the dead go to Heaven). Indeed, it is not even clear whether supernatural claims are themselves distinct - how likely it is, for example, that a person will report a belief in God but deny an afterlife, or vice versa.

To make matters more complicated, explicit measures of belief generally depend on individuals' introspection and self-reports, but there are many reasons why individuals might not accurately or honestly report their religious beliefs and behaviors to inquiring experimenters. One theoretically trivial reason is that they may be reluctant to share beliefs that they think are nonnormative, or that the experimenter (a scientist after all) will judge harshly. More interestingly, beliefs and attitudes may not be consistent over time, and answers to questionnaire items may represent less a readout of a participant's internal representation than a product of what thoughts were salient at the time the questions were asked.

In a study by Salancik and Conway ([66], Study 1), for example, participants were subtly led to assert that they had performed pro- or anti-religious behaviors, and consequently reported attitudes toward being religious that were consistent with the newly salient information. Participants were asked, for example, whether they prayed "frequently" or (in a different experimental 
condition) "on occasion," questions they tended to deny or confirm, respectively, independent of the objective frequency of their behavior, and which led them to under or overestimate their religiosity, respectively. These and other demonstrations of the malleability of beliefs (e.g., the phenomenon of "choice blindness," in which participants fail to notice that the experimenter has sneakily swapped the chosen option for an unchosen one [35], [36], [52]), suggest that some beliefs, perhaps even confidently held ones, are tenuous, if not entirely illusory.

Perhaps most interesting, people may fail to report explicit beliefs because they don't know, or may be incorrect about, what they believe. The still-controversial idea that experimental participants "tell more than they know" [54] is at least consistent with the general understanding of "implicit beliefs," sometimes defined as those that are "introspectively unidentified (or inaccurately identified)" [32, p. 5]. That is, like explicit beliefs, they are, in principle, stable and measurable ${ }^{2}$ associations between objects and characteristics, but unlike explicit beliefs, they are not directly accessible to consciousness and must be inferred indirectly (e.g., through behavior).

According to contemporary models in the cognitive science of religion, theory of mind (i.e., the tendency to attribute psychological states to others), essentialism (i.e., the idea that objects and events have an immutable essence or purpose), and hyperactive agency detection (i.e., ascribing intentional agency to inanimate objects) are some of the underlying mechanisms that promote implicit religious beliefs about the afterlife, existential meaning, and supernatural agents [3], [6], [9], [11], [28], [33], [38], [40]. Although these religious intuitions can be consciously overridden, they are powerful and ancient features of the human brain. Thus, rejecting implicit beliefs is cognitively effortful work, which may explain why religion is so ubiquitous and persistent in our species: the beliefs subserving religious practices and institutions are inaccessible and cognitively difficult to reject.

\section{Dual Process and Continuum Theories}

The distinction between explicit and implicit cognitions is not fully understood, though they are often integrated into so-called dual process or continuum theories (e.g., [4], [17], [20], [55], [72]). Such approaches can be seen as an attempt to reconcile implicit and explicit beliefs. Generally speaking, dual process models propose two qualitatively distinct types of reasoning processes: "Type 1," associated with intuitive, spontaneous, automatic, unconscious, and implicit mechanisms; and "Type 2," associated with analytic, reflective, controlled, reasoned, and explicit mechanisms. Though there is not complete consensus on the relation between the levels (e.g., which is "better"; which is more fundamental), a number of theories conceptualize them hierarchically, with Type 1 processes providing quick, consciously unfiltered responses to stimuli, which can then be adjusted and corrected, via Type 2 processing, if time and cognitive resources permit. For example, in Devine's [19] influential model of prejudice, individuals are assumed to activate stereotypes of minority groups automatically, upon encountering a member or symbol of the group, regardless of any conscious desire to remain unbiased. The initial reactions are then consciously overridden if and when the individual becomes aware of them, assuming he or she has the inclination and cognitive resources to do so. Similarly, dual process models might characterize religious beliefs to be spontaneous, affective, nonreflective responses to the world that have failed to be overridden by more effortful cognitive reflection.

Religious individuals will naturally be skeptical of an account that treats their beliefs as relatively unsophisticated reactions awaiting reasoned disconfirmation, but there is some (controversial) evidence that religious thought is, at least, associated with Type 1 processing. Believers, for example, form more liberal automatic associations (e.g., [65]), prefer intuition to analytic thought ([1], [69]), and trust their intuitions more [48] than nonbelievers. Conversely, nonbelievers show an increased reliance on analytical thinking [29], [58], [59], [60], [69]. Gervais and Norenzayan [29], for example, reported a correlation between participants' religious belief and their tendency to provide the intuitive (but incorrect) answers to riddles (e.g., If a bat and ball cost $\$ 1.10$ together, and the bat costs $\$ 1$ more than the ball, what does the ball cost?). The researchers 
also found that "thinking" primes, such as exposure to Rodin's sculpture, The Thinker, reduced religious belief relative to control primes, although subsequent research has failed to replicate these effects ([29], [68]). More recently, Farias and colleagues [21] further questioned the simple mapping of cognitive processing and religious belief, failing to find a relationship between intuitive thinking style and religious identification or behavior, or any effect of intuition when experimentally manipulated (by overloading working memory, or suppressing inhibition via brain stimulation).

\section{What Kind of "Belief" is Behavior?}

It is against this uncertain theoretical backdrop that we now consider what "behaving as if" one believes might mean. What, for example, does a person's reluctance to sell their soul tell us about their belief in the soul, whether explicit or implicit? Psychological research points to three possible answers.

\subsection{Behavior is Independent of Belief}

One possible answer is that behavior tells us nothing at all about belief. Gendler [27] treats behavior that conflicts with belief as an independent construct, coining the term alief to refer to the automatic or habitual response to stimuli that conflicts with one's explicit beliefs. For example, a person may respond as if she is at risk of falling when standing on the glass "Skywalk" that spans the Grand Canyon (e.g., she may feel anxiety, grip the handrails, tremble, etc.), but these reactions do not necessarily reflect her belief that she in danger. She may express complete confidence in the engineers and safety inspectors who built and certified the bridge, and even (more controversially) unconsciously associate the bridge with safety, but her body may disagree. Similarly, people can feel genuine emotions while watching a movie they know to be fictional or they may knock on wood with no expectation of positive results. Such phenomena, Gendler suggests, show only that sensory stimuli can activate concept association patterns, including behaviors, beliefs, attitudes, and emotions. These processing mechanisms are insensitive to whether the stimuli are real, imagined, believed, or not believed.

According to this model of alief, people need not believe in the soul to be reluctant to sell theirs; they need only have associated the soul with value. They do not need to believe in ghosts to feel fear when told a ghost is present; they need only have associated the emotion of fear with the concept of ghosts (or any other fear-valenced target, for that matter, such as the Devil or werewolves). In general, "true" or "hidden" belief should not necessarily be inferred from one's behavior or bodily reactions to such emotionally laden primes. Rather, such responses are automatically generated from existing innate or learned associations, having no prima facie epistemological value.

\subsection{Behavior is Indicative of Belief}

A second answer is to assume that while behavior is not the same as belief, it tends to be associated with belief. Although the association is intuitively causal - we are afraid of ghosts because we believe they are real - it need not be. Indeed, attitude researchers have historically assumed that beliefs, emotions, and behaviors are three components of a single construct (e.g., [64], [2], [15].) We are not fearful of ghosts because we believe them to be real; our belief in ghosts, our negative emotions, and our behavioral response, collectively make up our "attitude" toward ghosts.

Even if the components do not directly influence one another, however, they may exert indirect influence via individuals' motivation for consistency (as in cognitive dissonance theory; [23]) or via their logical inferences about the meaning of their behavior (as in Self Perception Theory; [8]). In the former case, behavior that is inconsistent with belief is assumed to create measurable physiological discomfort, which people are motivated to assuage by alternating one or 
both of the contradictory components. In the latter case, behavior is simply used as evidence from which belief can be logically inferred. Thus, on the first account, a fearful response to a ghostly apparition motivates the skeptic to believe that ghosts exist, in order to obviate the uncomfortable contradiction between their fear of ghosts and their skepticism about their existence. On the second account there is no discomfort to assuage; the skeptic merely infers (as any observer might) that he believes in ghosts more than he thought (else why would he be fearful of one?). In either case, behavior in this case is functionally inseparable from belief, not an orthogonal construct that may or may not constitute evidence of it.

\subsection{Behavior is Belief}

A third answer goes even farther in terms of the primacy of behavior, proposing that behavior is not just a component of a holistic construct, of which beliefs and emotions are also parts, but rather constitutes the very means by which beliefs and emotions are represented. According to "embodiment" theories, our beliefs concerning ghosts, for example, are not stored as abstract, amodal mental representations, but rather in the pattern of bodily changes and movements characteristic of our interactions with ghosts (whether real or imagined). Thus, the question of whether belief causes or is caused by behavior, is meaningless; belief $i s$ behavior. To believe that ghosts are real is to behave as though they are, and the awareness that one believes in ghosts follows rather than precedes that behavior.

Although various forms of embodied representation have been espoused by philosophers for centuries, the idea that knowledge is not necessarily stored as abstract symbols is a relatively recent approach in cognitive science (see [7], for an historical review). Its re-emergence has gained momentum from recent empirical findings that demonstrate the bi-directional relationship between thoughts (and emotions) and behavior. In most embodiment frameworks, perception of an object activates behavior that is associated with that object and, conversely, the associated behavior can facilitate or prime its perception. The presentation of a mug, for example, prompts motor movements required for grasping it [74], and objects are more easily recognized when preceded by other objects that required similar (versus incongruent) motor skills [37]. Behavioral simulations in social contexts show similar effects. For instance, participants asked to hold a pen between their teeth, without it touching their lips (i.e., a simulation of a smile), report more positive emotions [74] than participants who hold a pen in their lips (a simulation of a frown); participants instructed to slump report more negative emotions than those who sit upright [73]; and participants who nod their head, simulating agreement, report more agreement with an editorial than participants who turn their head side to side [76]. Recent developments in virtual reality have made it possible to embody physical states - and other people - in more literal ways, with intriguing results [50].

In its strongest form, the embodied cognition view renders moot the question of whether "behaving as if one believes" shows that one "really" believes, because those two claims amount to the same thing: religious belief involves simply the behaviors and bodily states associated with religious practice. Even a weaker form in which belief is directly influenced by behavior (but not synonymous with or wholly represented by it) would call into question the practical value of distinguishing behavior and belief. It might be, in a behavioral extension of self-perception theory, that skeptics who fear ghosts subsequently come to believe in them, while those who practice their religion without believing it discover they are more religious than they thought.

\section{Conclusion}

Religious belief and nonbelief, and the actions associated with believing, present a complicated yet seldom articulated puzzle to cognitive scientists working in this area. In many respects, the conversation among scholars seems to have outpaced the published findings, with many of the relevant concepts remaining too ambiguous for any conclusions to be drawn about their role in causality. This is especially so, as we have argued throughout, with the relationships between 
implicit and explicit supernatural thinking, and also behaviors (or physiological responses) that conflict with the individual's overt beliefs. Some researchers have more or less asserted that subtle, unconscious responses captured in clever laboratory experiments reflect participants' "true supernatural beliefs." Yet our position is that the directionality is in fact unclear: these measurable responses could be products, causes, or simple correlates (i.e., epiphenomena) of belief. Future research in this area should therefore aim to systematically pit these hypotheses against each other. Only then can a clear, integrated model of religious belief (and nonbelief) and behavior begin to emerge.

\section{References}

1. Aarnio, K., Lindeman, M. Religious people and paranormal believers: Alike or different? Journal of Individual Differences 28 (1), 2007, pp. 1-9.

2. Bagozzi, R. P., Tybout, A. M., Craig, C. S., \& Sternthal, B. The construct validity of the tripartite classification of attitudes, Journal of Marketing Research 16 (1), 1979, pp. 88-95.

3. Banerjee, K., Bloom, P. "Everything happens for a reason": Children's beliefs about purpose in life events, Child Development 86 (2), 2015, pp. 503-518.

4. Bargh, J. A., Chartrand, T. L. The unbearable automaticity of being, American Psychologist 54 (7), 1999, pp. 462-479.

5. Barrett, J. L., Keil, F. C. Conceptualizing a nonnatural entity: Anthropomorphism in God concepts, Cognitive Psychology 31 (3), 1996, pp. 219-247.

6. Barrett, J. L., Lanman, J. A. The science of religious beliefs, Religion 38 (2), pp. 109-124.

7. Barsalou, L. W. Grounded cognition, Annual Review of Psychology 59, 2008, pp. 617-645.

8. Bem, D. J. Self-perception: An alternative interpretation of cognitive dissonance phenomena, Psychological review 74 (3), 1967, pp. 183-200.

9. Bering, J. The belief instinct: The psychology of souls, destiny, and the meaning of life, WW Norton \& Company, 2011.

10. Bering, J. M. Intuitive conceptions of dead agents' minds: The natural foundations of afterlife beliefs as phenomenological boundary. Journal of Cognition and Culture 2 (4), 2002, pp. 263-308.

11. Bering, J. M. The folk psychology of souls, Behavioral and Brain Sciences 29 (5), 2006, pp. 453-498.

12. Bering, J. M., Bjorklund, D. F. The natural emergence of reasoning about the afterlife as a developmental regularity, Developmental Psychology 40 (2), 2004, pp. 217-233.

13. Bering, J. M., McLeod, K., \& Shackelford, T. K. Reasoning about dead agents reveals possible adaptive trends, Human Nature 16 (4), 2005, pp. 360-381.

14. Bloom, P. Religion is natural, Developmental Science 10 (1), 2007, pp. 147-151.

15. Breckler, S. J. Empirical validation of affect, behavior, and cognition as distinct components of attitude, Journal of Personality and Social Psychology 47 (6), 1984, pp. 1191-1205.

16. Chatterjee, S. Hindu pilgrimages, pp. 269-279, In A. Wilder-Smith, E. Schwartz, \& M. Shaw (eds.), Travel medicine: Tales behind the science, Oxford, UK: Elsevier, 2007.

17. Chen, S., Chaiken, S. The heuristic-systematic model in its broader context, Dual-process theories in social psychology 15, 1999, pp. 73-96.

18. Connors, M. H., Halligan, P. W. A cognitive account of belief: a tentative road map, Frontiers in Psychology 5, 2015, p. 1588.

19. Devine, P. G. Stereotypes and prejudice: Their automatic and controlled components, Journal of Personality and Social Psychology 56 (1), 1989, pp. 5-18.

20. Dijksterhuis, A., Nordgren, L. F. A theory of unconscious thought, Perspectives on Psychological Science 1 (2), 2006, pp. 95-109.

21. Farias, M. et al. Supernatural belief is not modulated by intuitive thinking style or cognitive inhibition, Scientific Reports 7 (1), 2017, p. 15100.

22. Fazio, R. H. Attitudes as object-evaluation associations of varying strength, Social Cognition 25 (5), 2007, pp. 603-637. 
23. Festinger, L. A theory of cognitive dissonance, vol. 2, Palo Alto, CA, US: Stanford University Press, 1962.

24. Fuller, C. J. Camphor flame: Popular Hinduism and society in India, Princeton, NJ: Princeton University Press, 2004.

25. Gawronski, B., Bodenhausen, G. V. Associative and propositional processes in evaluation: an integrative review of implicit and explicit attitude change, Psychological Bulletin 132 (5), 2006, pp. 692-731.

26. Gawronski, B., De Houwer, J. Implicit measures in social and personality psychology, pp. 283310, In H. T. Reis, C. M. Judd (eds.), Handbook of research methods in social and personality psychology ( $2^{\text {nd }}$ ed.), New York, NY: Cambridge University Press, 2014.

27. Gendler, T. S. Alief and belief, The Journal of Philosophy 105 (10), 2008, pp. 634-663.

28. Gervais, W. M. Religious cognition, pp. 81-105, In V. Saroglou (ed.), Religion, personality, and social behavior, Psychology Press, 2013.

29. Gervais, W. M., Norenzayan, A. Analytic thinking promotes religious disbelief, Science 336 (6080), 2012, pp. 493-496.

30. Gervais, W. M., et al. Analytic atheism: A cross-culturally weak and fickle phenomenon? Judgment and Decision Making 13 (3), 2018, pp. 268-274.

31. Gomes, C. M., McCullough, M. E. The effects of implicit religious primes on dictator game allocations: A preregistered replication experiment, Journal of Experimental Psychology: General 144 (6), 2015, e94-e104.

32. Greenwald, A. G., Banaji, M. R. Implicit social cognition: Attitudes, self-esteem, and stereotypes, Psychological Review 102 (1), 1995, pp. 4-27.

33. Guthrie, S. E. Faces in the clouds: A new theory of religion, New York: Oxford University Press, 1993.

34. Haidt, J., Bjorklund, F., \& Murphy, S. Moral dumbfounding: When intuition finds no reason, unpublished manuscript, 2000.

35. Hall, L., Johansson, P., \& Strandberg, T. Lifting the veil of morality: Choice blindness and attitude reversals on a self-transforming survey, PLOS ONE 7 (9), 2012, e45457.

36. Hall, L., Johansson, P., Tärning, B., Sikström, S., \& Deutgen, T. Magic at the marketplace: Choice blindness for the taste of jam and the smell of tea, Cognition 117 (1), 2010, pp. 54-61.

37. Helbig, H. B., Graf, M., \& Kiefer, M. The role of action representations in visual object recognition, Experimental Brain Research 174 (2), 2006, pp. 221-228.

38. Heywood, B. T., Bering, J. M. "Meant to be": How religious beliefs and cultural religiosity affect the implicit bias to think teleologically, Religion, Brain \& Behavior 4 (3), 2014, pp. 183-201. 39. Järnefelt, E., Canfield, C. F., \& Kelemen, D. The divided mind of a disbeliever: Intuitive beliefs about nature as purposefully created among different groups of non-religious adults, Cognition 140, 2015, pp. 72-88.

40. Jong, J. Explaining Religion (Away?), Sophia 52 (3), 2013, pp. 521-533.

41. Jong, J. Beliefs are Object-Attribute Associations of Varying Strength, Contemporary Pragmatism 15 (3), 2018, pp. 284-301.

42. Kelemen, D., Rosset, E. The human function compunction: Teleological explanation in adults, Cognition 111 (1), 2009, pp. 138-143.

43. Kelemen, D., Rottman, J., \& Seston, R. Professional physical scientists display tenacious teleological tendencies: Purpose-based reasoning as a cognitive default, Journal of Experimental Psychology: General 142 (4), 2013, pp. 1074-1083.

44. Keysar, A., Navarro-Rivera, J. A world of atheism: Global demographics, pp. 553-586, In S. Bullivant, M. Ruse (eds.), The Oxford handbook of atheism, Oxford, UK: Oxford University Press, 2013.

45. Laurin, K., Kay, A. C., \& Fitzsimons, G. M. Divergent effects of activating thoughts of God on self-regulation, Journal of Personality and Social Psychology 102 (1), 2012, pp. 4-21.

46. Lebreton, L. C., Van der Zwet, J., Damsteeg, J. W., Slat, B., Andrady, A., \& Reisser, J. River plastic emissions to the world's oceans, Nature Communications 8, 2017, p. 15611. 
47. Lindeman, M., Heywood, B., Riekki, T., \& Makkonen, T. Atheists become emotionally aroused when daring God to do terrible things, International Journal for the Psychology of Religion 24 (2), 2014, pp. 124-132.

48. Lindeman, M., Svedholm-Häkkinen, A. M., \& Lipsanen, J. Ontological confusions but not mentalizing abilities predict religious belief, paranormal belief, and belief in supernatural purpose, Cognition 134, 2015, pp. 63-76.

49. Maclean, K. Pilgrimage and power: The Kumbh Mela in Allahabad, 1765-1954, Oxford, UK: Oxford University Press, 2008.

50. Maister, L., Slater, M., Sanchez-Vives, M. V., \& Tsakiris, M. Changing bodies changes minds: owning another body affects social cognition, Trends in Cognitive Sciences 19 (1), 2015, pp. 6-12.

51. McKay, R. T., Dennett, D. C. Our evolving beliefs about evolved misbelief, Behavioral and Brain Sciences 32 (6), 2009, pp. 541-561.

52. McLaughlin, O., Somerville, J. Choice blindness in financial decision making, Judgment and Decision Making 8 (5), 2013, pp. 561-572.

53. Moors, A., Spruyt, A., \& De Houwer, J. In search of a measure that qualifies as implicit: Recommendations based on a decompositional view of automaticity, pp. 19-35, In B. Gawronski, B. K. Payne (eds.), Handbook of implicit social cognition: Measurement, theory, and applications, New York, NY: Guilford, 2010.

54. Nisbett, R. E., Wilson, T. D. Telling more than we can know: Verbal reports on mental processes, Psychological Review 84, 1977, pp. 231-259.

55. Nosek, B. A. Implicit-explicit relations. Current Directions in Psychological Science 16 (2), 2007, pp. 65-69.

56. Oman, D. Defining religion and spirituality, pp. 23-47, In R. F. Paloutzian, C. L. Park (eds.), Handbook of the psychology of religion and spirituality $\left(2^{\text {nd }}\right.$ ed.), New York: Guilford, 2013.

57. Pechey, R., Halligan, P. W. Exploring the folk understanding of belief: Identifying key dimensions endorsed in the general population, Journal of Cognition and Culture 12 (1-2), 2012, pp. 81-99.

58. Pennycook, G., Cheyne J. A., Barr, N., Koehler, D. J., \& Fugelsang, J. A. On the reception and detection of pseudo-profound bullshit, Judgment and Decision Making 10 (6), 2015, pp. 549-563.

59. Pennycook, G., Cheyne, J. A., Seli, P., Koehler, D. J., \& Fugelsang, J. A. Analytic cognitive style predicts religious and paranormal belief, Cognition 123 (3), 2012, pp. 335-346.

60. Pennycook, G., Ross, R. M., Koehler, D. J., \& Fugelsang, J. A. Atheists and agnostics are more reflective than religious believers: Four empirical studies and a meta-analysis, PLOS ONE 11 (4), 2016, e0153039.

61. Pew Center on Religion and Public Life. The Global Religious Landscape, Washington D.C.: Pew Forum on Religion and Public Life, 2012.

62. Preston, J. L., Ritter, R. S., \& Hepler, J. Neuroscience and the soul: Competing explanations for the human experience, Cognition 127 (1), 2013, pp. 31-37.

63. Randolph-Seng, B., Nielsen, M. E. Honesty: One effect of primed religious representations, The International Journal for the Psychology of Religion 17 (4), 2007, pp. 303-315.

64. Rosenberg, M. J., Hovland, C. I., McGuire, W. J., Abelson, R. P., \& Brehm, J. W. Attitude organization and change: An analysis of consistency among attitude components (Yales studies in attitude and communication), Oxford, England: Yale University Press, 1960.

65. Rozin, P., Nemeroff, C. Sympathetic magical thinking: The contagion and similarity "heuristics", pp. 201-216, In T. Gilovich, D. Griffin, \& D. Kahneman (eds.), Heuristics and biases: The psychology of intuitive judgment, New York, NY, US: Cambridge University Press. 2002.

66. Salancik, G. R., Conway, M. Attitude inferences from salient and relevant cognitive content about behavior, Journal of Personality and Social Psychology 32 (5), 1975, pp. 829-840.

67. Sanchez, C., Sundermeier, B., Gray, K., \& Calin-Jageman, R. J. Direct replication of Gervais \& Norenzayan (2012): No evidence that analytic thinking decreases religious belief, PLOS ONE 12 (2), 2017, e0172636. 
68. Shariff, A. F., \& Norenzayan, A. God is watching you: Priming God concepts increases prosocial behavior in an anonymous economic game. Psychological Science 18(9), 2007, pp. 803809.

69. Shenhav, A., Rand, D. G., \& Greene, J. D. Divine intuition: Cognitive style influences belief in God, Journal of Experimental Psychology: General 141 (3), 2012, pp. 423-428.

70. Smith, S., Alogna, V. K., Balkcom, E. R., Halberstadt, J. B., \& Bering, J. M. Challenges of religious skepticism: Do extinctivists fear a visit from the dead? Poster presented at the annual meeting of the Society for Personality and Social Psychology, Portland, OR, USA.

71. Sosis, R., Alcorta, C. Signaling, solidarity, and the sacred: The evolution of religious behavior, Evolutionary Anthropology: Issues, News, and Reviews: Issues, News, and Reviews 12 (6), 2003, pp. 264-274.

72. Sperber, D. Intuitive and reflective beliefs, Mind \& Language 12 (1), 1997, pp. 67-83.

73. Stepper, S., Strack, F. Proprioceptive determinants of emotional and nonemotional feelings, Journal of Personality and Social Psychology 64 (2), 1993, pp. 211-220.

74. Strack, F., Martin, L. L., \& Stepper, S. Inhibiting and facilitating conditions of the human smile: A nonobtrusive test of the facial feedback hypothesis, Journal of Personality and Social Psychology 54 (5), 1988, pp. 768-777.

75. Tucker, M., Ellis, R. On the relations between seen objects and components of potential actions, Journal of Experimental Psychology: Human Perception and Performance 24 (3), 1998, pp. 830-846.

76. Wells, G. L., Petty, R. E. The effects of over head movements on persuasion: Compatibility and incompatibility of responses, Basic and Applied Social Psychology 1 (3), 1980, pp. 219-230.

77. Willard, A. K., Norenzayan, A. Cognitive biases explain religious belief, paranormal belief, and belief in life's purpose, Cognition 129 (2), 2013, pp. 379-391.

78. Zuckerman, P. Atheism: Contemporary numbers and patterns, pp. 47-66, In M. Martin (ed.), The Cambridge companion to atheism, Cambridge, UK: Cambridge University Press, 2007.

\section{Notes}

1. Personal communication (2017) confirmed that participants were asked "do you believe you have a soul."

2. Implicit belief should not be confused with implicit measures. A measure is implicit to the extent that responses to it are difficult to control, are nonconscious, are not cognitively effortful, and unintentional [26], [53]. 